\title{
Efeito da Suplementação Protéica a Pasto sobre Consumo de Forragens, Ganho de Peso e Condição Corporal, em Vacas Nelore ${ }^{1}$
}

\author{
José Reinaldo Mendes Ruas ${ }^{2}$, Ciro Alexandre Alves Torres ${ }^{3}$, Sebastião de Campos Valadares \\ Filho $^{3}$, José Carlos Pereira ${ }^{3}$, Lazáro Eustáquio Borges ${ }^{2}$, Alberto Marcatti Neto ${ }^{2}$
}

RESUMO - O objetivo do presente trabalho foi verificar o efeito da utilização de concentrado protéico, durante a época de verão, sobre consumo de forragem e variação no ganho de peso e no escore da condição corporal após o parto. Foram utilizadas 51 vacas paridas da raça Nelore, distribuídas ao acaso nos seguintes tratamentos: T0 = sem suplementação; T1 = suplementação com $1 \mathrm{~kg}$; e T2 = suplementação com $2 \mathrm{~kg}$ de concentrado contendo 40,8\% de PB, durante 105 dias. Neste período, foram determinados o escore corporal e o peso. Para determinar o consumo, utilizaram-se o marcador externo óxido de cromo, em dose única diária de 20 g, e o marcador interno FDA indigestível das extrusas, coletadas por meio de fístulas esofágicas. A suplementação não influenciou o consumo de MS de pasto, que ficou em torno de $9,87 \mathrm{~kg} \mathrm{MS} / \mathrm{dia}$, correspondente a 2,13\% do peso vivo, mas o consumo total de MS foi superior nos tratamentos T1 e T2. Escore da condição corporal, ganho de peso diário e peso final das vacas mostraram-se superiores nos animais suplementados em relação aos não-suplementados. Não foi observada diferença entre os pesos das crias ao final do período experimental.

Palavras-chave: consumo de pasto, escore corporal, ganho de peso, suplementação protéica

\section{Effect of Protein Supplementation at Pasture on Forage Intake, Weight Gain and Body Condition, in Nellore Cows}

\begin{abstract}
Fifty-one postpartum Nellore cows were used to study the effect of the utilization of protein concentrate, during the summer time, on the forage intake, weight gain and body condition score changes after parturition of Nellore cows. The animals were randomly allotted in the following treatments: T0 - without supplementation; T1 - supplemented with $1 \mathrm{~kg}$ and T2 - supplemented with $2 \mathrm{~kg}$ of concentrate with $40.8 \%$ of crude protein, during 105 days. During this period, body score and body weight were determined. In order to determine the intake, an external marker chromium oxide, in a daily dose of $20 \mathrm{~g}$, and an internal marker (indigestible FDA of extrusa collected by esophageal fistula) were used. The supplementation with concentrate did not affect the dry matter (DM) intake from the pasture, that was around $9.87 \mathrm{~kg} \mathrm{DM} / \mathrm{day}$, corresponding to $2.13 \%$ of the live weight, but the total $\mathrm{DM}$ intake was greater in the animals of $\mathrm{T} 1$ and $\mathrm{T} 2$. Body condition score, daily weight gain and final weight of the cows were greater in the supplemented animals as compared to the non-supplemented treatment. There was no difference among the calves weights at the end of the experimental period.
\end{abstract}

Key Words: condition score, pasture intake, protein supplementation, body weight gain

\section{Introdução}

O monitoramento do escore da condição corporal no pré e pós-parto, de maneira que os animais possam parir em boa condição, o que deve permanecer no pósparto, é a prática de manejo desejada. A infertilidade no pós-parto pode ser causada por falta de involução uterina, ciclos estrais curtos e anestro, sendo o anestro a maior causa. Podem estar envolvidas, ainda, a estação do ano, a raça e a distocia, sendo a nutrição e amamentação as de maior importância (SHORT et al., 1990; RANDEL, 1990). Em regime de alimentação, em que o pasto é a única fonte de alimento, a manutenção de bom estado corporal e o ganho de peso ocorrem quando as vacas estão não estão em lactação. Entretanto, em vacas recém paridas, ganhos de peso e de escore da condição corporal podem requerer período de suplementação, caso as pastagens não apresentem valor nutritivo adequado e sejam manejadas de maneira inadequada, ou em condição de clima tropical no período correspondente à época da seca. Escore da condição corporal e variação de peso após o parto estão relacionados com performance reprodutiva. Vacas que perdem acima de $10 \%$ de seu peso após o parto até a estação de monta, ou que se apresentam com escore

\footnotetext{
${ }^{1}$ Parte da Tese de Doutorado do primeiro autor apresentada ao DZO/UFV - Pesquisa Financiada pela FAPEMIG.

2 Pesquisador da EPAMIG - Viçosa, Belo Horizonte, Patos de Minas - E.mail: jrmruas@mail.ufv.br

3 Professor do Departamento de Zootecnia - UFV - Viçosa, MG.
} 
inferior a 4,5 (escala de 1 a 9) ao parto e durante a estação de acasalamento, podem ter esta performance comprometida (DIAS, 1991; WETTEMANN, 1994). A opção de promover ganho na condição corporal deve ser conduzida no intuito de melhorar a taxa de fertilidade. Assim, uso de pastagens de boa qualidade, suplementação, desde que não promova a substituição do pasto, e custo são variáveis que devem ser consideradas (KUNKLE et al., 1994).

O princípio básico na suplementação a pasto é evitar efeito substitutivo e promover aumento da ingestão e da digestibilidade das forragens. Quando se suplementa dieta forrageira, deficiente em proteína, com alimentos ricos em proteína, como farelo de soja ou de algodão, aumenta em grande parte o consumo do volumoso (LUSBY e GILL, 1996).

Os objetivos do presente trabalho foram verificar o efeito da utilização de concentrado, sobre consumo de forragem e variação no ganho de peso e no escore da condição corporal após o parto.

\section{Material e Métodos}

O experimento foi conduzido no período de outubro de 1996 a abril de 1997, na fazenda experimental de Sertãozinho - EPAMIG, localizada no município de Patos de Minas - MG $\left(896,12\right.$ metros de altitude, $18^{\circ}$ 36' latitude sul e $46^{\circ} 31^{\prime}$ ' longitude a oeste de Greenwich).

As pastagens eram formadas predominantemente por capim-jaraguá (Hyparrhenia rufa spp.) e a topografia apresentava relevo levemente ondulado. Os piquetes possuíam cochos cobertos para sal mineral e bebedouros de cimento para água.

As análises laboratoriais foram realizadas no Laboratório de Nutrição Animal do Departamento de Zootecnia da UFV.

Foram utilizadas 51 vacas paridas da raça Nelore, identificadas com numeração a fogo e selecionadas para atender às seguintes exigências: ocorrência do parto entre outubro de 1996 e janeiro de 1997, ser multípara e apresentar bom estado de saúde.

À medida que ocorria o parto, as vacas eram distribuídas nos tratamentos a seguir:

T0 - Sem suplementação;

T1 - Suplementação com $1 \mathrm{~kg}$ de concentrado por dia; e

T2 - Suplementação com $2 \mathrm{~kg}$ de concentrado por dia.

Todas as vacas foram mantidas em um único pasto de, aproximadamente, 50 hectares, sob pastejo contínuo, juntamente com suas crias. A suplementação foi realizada pela manhã durante 15 semanas no pósparto, quando as vacas foram separadas por tratamento e levadas ao cocho, com a ração já distribuída. Após o consumo da ração, que levava cerca de 20 minutos, todas as vacas foram reunidas novamente $\mathrm{e}$ soltas no mesmo pasto.

A ração concentrada continha $60 \%$ de farelo de soja e $40 \%$ de farelo de algodão.

Criou-se uma metodologia simplificada para determinar o escore da condição corporal das vacas, que foi realizado ao parto e a cada 15 dias, por um único técnico, seguindo os seguintes parâmetros:

baixo $=$ cobertura muscular ruim, de forma que ossos como costelas, processos vertebrais, ísquios e íleos pudessem ser bem delimitados; neste caso, era atribuída a nota três;

médio $=$ cobertura muscular boa, sem deposição de gordura, em que as costelas e os processos vertebrais foram difíceis de serem identificados; a nota atribuída foi quatro; e

alto $=$ cobertura muscular boa, com deposição de gordura na inserção da cauda, costado, escapula, região lombar. Nestes animais, a identificação dos ossos foi difícel; a nota atribuída foi cinco.

Para determinação do escore, o animal foi colocado no tronco de contenção, onde foi realizada a palpação de costelas, dorso, lombo e ao redor da inserção da cauda. Foram atribuídas notas intermediárias $( \pm 0,5)$, quando o animal não se enquadrava bem em uma das categorias citadas.

O estudo para determinar o consumo foi realizado em dois períodos, nos meses de fevereiro e abril de 1997, utilizando-se 15 vacas paridas em cada período, cinco por tratamento, a saber: sem suplementação (T0), suplementação com $1 \mathrm{~kg}$ vaca/dia (T1) e suplementação com $2 \mathrm{~kg}$ vaca/ dia (T2). As vacas utilizadas foram mantidas no mesmo manejo e local das demais do experimento de suplementação.

O consumo diário do pasto (matéria seca) foi estimado para as vacas dos três tratamentos experimentais, utilizando-se, como indicadores externo e interno, óxido crômico $\left(\mathrm{Cr}_{2} \mathrm{O}_{3}\right)$ e fibra em detergente ácido indigestível (FDAi), respectivamente.

Em cada período, as vacas receberam, durante 15 dias, às $10 \mathrm{~h}$, uma porção diária de $20 \mathrm{~g} \mathrm{de} \mathrm{Cr}_{2} \mathrm{O}_{3}$, acondicionadas em cartucho de papel. O óxido crômico foi introduzido diretamente no esôfago dos animais, usando-se um tubo de PVC de $3 / 4$ de polegada, adaptado para essa finalidade. 


\section{Rev. bras. zootec.}

Nos últimos cinco dias, simultaneamente com o fornecimento da porção de óxido crômico, coletaram-se aproximadamente 150 gramas de fezes, diretamente do reto das vacas. As amostras por animal e período foram acondicionadas em único saco plástico, constituindo, assim, uma amostra composta por animal por período.

Para se amostrar o pasto consumido em cada época, foram utilizados três novilhos de sobreano, fistulados no esôfago. As amostragens foram realizadas no período da manhã, durante cinco dias, correspondentes ao período de coleta de fezes das vacas. Os animais foram mantidos em jejum por 14 horas e, logo após, levados ao pasto experimental. As amostras foram congeladas por animal e período, formando assim uma amostra composta.

No Laboratório de Nutrição Animal do Departamento de Zootecnia da UFV, foram processadas as amostras (pré-secagem e moagem) e determinados os teores de matéria seca (MS), nitrogênio total (Nt), fibra em detergente neutro (FDN), fibra em detergente ácido (FDA) e cromo, conforme metodologia descrita por SILVA (1990). Para determinar a fibra em detergente ácido indigestível (FDAi), foi realizada a digestão in vitro, por um período de 144 horas, de acordo com a metodologia proposta por COCHRAN et al. (1986).

Para determinar o consumo, foram utilizadas as seguintes fórmulas:

g MS fecal excretada $=\frac{}{\% \text { de cromo na matéria seca fecal }}$

kg MS fecal excretada $\mathrm{x}$ $\%$ FDAi nas fezes

$\mathrm{kg} \mathrm{MS}$ consumida $=\frac{\% \text { de FDAi na forragem }}{\% \text {. }}$

Para os tratamentos com fornecimento de concentrado, determinou-se o consumo de MS de forragem, pelo desconto de FDAi relativo ao concentrado do FDAi das fezes.

$\mathrm{Na}$ análise estatística, foi utilizado o programa SAEG 7.0, aplicando-se análise de variância, a fim de observar as diferenças para escore corporal, média de ganho diário de peso vivo, peso da vaca e do bezerro e consumo de pasto, tendo como fonte de variação os tratamentos e os períodos de coleta dentro de tratamento. As diferenças observadas na análise de variância foram testadas utilizando-se teste de média e análise de regressão para tratamento e período dentro de cada tratamento, respectivamente.

\section{Resultados e Discussão}

As médias de consumo diário de MS de pasto e total encontram-se na Tabela 1.

Quando se calculou a média de consumo diário de MS de pasto, não se verificaram diferenças entre os animais dos três tratamentos $(\mathrm{P}>0,05)$, todavia, para o consumo de matéria seca total, em quilogramas por dia e gramas por unidade de tamanho metabólico (g MS/kg ${ }^{0.75}$ ), detectaram-se diferenças significativas $(\mathrm{P}<0,05)$. Em ambos os casos, os valores foram inferiores para as vacas que não receberam concentrado (T0).

Com relação ao consumo em percentual de peso vivo, os valores encontrados para consumo de MS total foram 2,$11 ; 2,39$; e 2,42 para os tratamentos $\mathrm{T} 0$, T1 e T2, respectivamente. A média de consumo de MS de pasto de 9,87 kg MS/dia está próximo do

Tabela 1 - Média de consumo diário de matéria seca (MS) de pasto e total em vacas Nelore, recebendo diferentes níveis de suplemento protéico

Table 1 - Average daily intake of pasture and total dry matter intake of Nellore cows, receiving different levels of protein supplement

\begin{tabular}{|c|c|c|c|}
\hline \multirow{3}{*}{$\begin{array}{l}\text { Tratamento } \\
\text { Treatment }\end{array}$} & \multicolumn{3}{|c|}{$\begin{array}{c}\text { Média de consumo } \\
\text { Average intake }\end{array}$} \\
\hline & $\mathrm{kg} \mathrm{MS}$ & \%peso vivo & $\mathrm{gMS} / \mathrm{kg}^{0,75}$ \\
\hline & kg DM & $\%$ live weight & $g D M / k g .75$ \\
\hline & \multicolumn{3}{|c|}{$\begin{array}{l}\text { MS de pasto } \\
\text { DM of pasture }\end{array}$} \\
\hline $\begin{array}{l}\text { Sem suplemento (T0) } \\
\text { Without supplement }\end{array}$ & 8,93 & 2,11 & 95,92 \\
\hline $\begin{array}{l}1 \mathrm{~kg} \text { suplemento }(\mathrm{T} 1) \\
1 \mathrm{~kg} \text { supplement }\end{array}$ & 10,40 & 2,21 & 102,94 \\
\hline $\begin{array}{l}2 \mathrm{~kg} \text { suplemento (T2) } \\
2 \mathrm{~kg} \text { supplement }\end{array}$ & 10,28 & 2,07 & 97,88 \\
\hline $\begin{array}{l}\text { Média } \\
\text { Mean }\end{array}$ & 9,87 & 2,13 & 98,92 \\
\hline $\mathrm{CV}(\%)$ & 15,44 & $\begin{array}{c}15,97 \\
\text { MS total } \\
\text { Total DM }\end{array}$ & 15,50 \\
\hline $\begin{array}{l}\text { Sem suplemento (T0) } \\
\text { Without supplement }\end{array}$ & $8,93^{\mathrm{b}}$ & 2,11 & $95,92^{\mathrm{b}}$ \\
\hline $\begin{array}{l}1 \mathrm{~kg} \text { suplemento }(\mathrm{T} 1) \\
1 \mathrm{~kg} \text { supplement }\end{array}$ & $11,27^{\mathrm{a}}$ & 2,39 & $111,63^{\mathrm{a}}$ \\
\hline $\begin{array}{l}2 \mathrm{~kg} \text { suplemento }(\mathrm{T} 2) \\
2 \mathrm{~kg} \text { supplement }\end{array}$ & $12,03^{\mathrm{a}}$ & 2,42 & $114,57^{\mathrm{a}}$ \\
\hline $\begin{array}{l}\text { Média } \\
\text { Mean }\end{array}$ & 10,74 & 2,31 & 107,37 \\
\hline $\mathrm{CV}(\%)$ & 14,18 & 17,74 & 14,27 \\
\hline
\end{tabular}

Médias, na coluna, seguidas de letras diferentes são diferentes $(\mathrm{P}<0,05)$ pelo teste SNK.

Means, within a column, followed by different letters are different $(P<.05)$ by SNK test. 
Tabela 2 - Médias e coeficiente de variação (CV) para escore da condição corporal ao parto (ESCP), escore ao final do experimento (ESCF), peso inicial (PESI), peso final (PESF), média de ganho diário (GMD) e peso do bezerro final (PEBF)

Table 2 - Means and coefficient of variation (CV) for score at parturition (SP), score in the end of the experiment (SEE), initial live weight (IW), final live weight (EW), daily weight gain (DWG) and live weight of calf in the end of experiment (WCEE)

\begin{tabular}{|c|c|c|c|c|}
\hline \multirow[b]{2}{*}{ Item } & \multicolumn{3}{|c|}{$\begin{array}{c}\text { Tratamento } \\
\text { Treatment }\end{array}$} & \multirow[b]{2}{*}{$\mathrm{CV}$} \\
\hline & T0 & $\mathrm{T} 1$ & $\mathrm{~T} 2$ & \\
\hline $\begin{array}{l}\mathrm{ESCP}(3-5) \\
S C\end{array}$ & 3,91 & 3,93 & 3,87 & 9,44 \\
\hline $\begin{array}{l}\text { ESCF (3 - 5) } \\
\text { SEE }\end{array}$ & $4,14^{\mathrm{b}}$ & $4,32^{\mathrm{b}}$ & $4,60^{\mathrm{a}}$ & 7,69 \\
\hline $\begin{array}{l}\text { PESI (kg) } \\
I W\end{array}$ & 424,76 & 435,35 & 448,29 & 7,64 \\
\hline $\begin{array}{l}\text { PESF }(\mathrm{kg}) \\
E W\end{array}$ & $451,63^{\mathrm{b}}$ & $473,12^{\mathrm{ab}}$ & $492,73^{a}$ & 7,20 \\
\hline $\begin{array}{l}\text { GMD }(\mathrm{kg}) \\
D W G\end{array}$ & $0,353^{\mathrm{b}}$ & $0,532^{\mathrm{a}}$ & $0,618^{a}$ & 32,16 \\
\hline $\begin{array}{l}\text { PEBF }(\mathrm{kg}) \\
W C E E\end{array}$ & 88,07 & 89,15 & 92,84 & 15,75 \\
\hline
\end{tabular}

Médias, na linha, seguidas de letras diferentes são diferentes $(P<0,05)$ pelo teste SNK.

Means, within a column, followed by different letters are different $(P<.05)$ by SNK test.

Tabela 3 - Média das análises dos teores de proteína bruta (PB), fibra em detergente neutro (FDN), fibra em detergente ácido (FDA) e fibra detergente ácido indigestível (FDA-i), expressos na matéria seca, do suplemento protéico e do pasto

Table 3 - Average contents in dry matter, crude protein $(C P)$, neutral detergent fiber (NDF), acid detergent fiber (ADF) and acid detergent fiber non-digestible (ADF-i) of the protein supplement and pasture

\begin{tabular}{lcccc}
\hline & \multicolumn{4}{c}{ Teor médio } \\
& Average content \\
\cline { 2 - 5 } Alimento & PB & FDN & FDA & FDA-i \\
Feed & NP & $N D F$ & $A D F$ & $A D F-i$ \\
\hline $\begin{array}{l}\text { Suplemento protéico } \\
\text { Protein supplement }\end{array}$ & 40,80 & 28,30 & 14,50 & 7,98 \\
$\begin{array}{l}\text { Extrusa - Pasto } \\
\text { Pasture - Extruse }\end{array}$ & 8,52 & 74,04 & 51,08 & 23,02 \\
\hline Ants & & & & \\
\hline
\end{tabular}

Análises realizadas no Laboratório de Nutrição do Departamento de Zootecnia da UFV.

Analyses made at Nutrition Lab of Animal Science Department. encontrado por ROSADO (1991), 9,52 kg/dia, determinado em vacas Nelore paridas em pastagens de capim colonião, enquanto a média dos valores observados de $2,13 \%$ do peso vivo e $98,92 \mathrm{~g} \mathrm{MS} /{ }^{0,75}$ foi numericamente inferior à obtida por ROSADO (1991), $2,52 \%$ e 112 g MS/kg ${ }^{0,75}$, respectivamente. Quando se considerou o consumo de MS total para os animais dos tratamentos suplementados, os resultados foram superiores aos de ROSADO (1991), quando expressos em quilograma de MS por dia, e similares, quando expressos em \% de peso vivo e grama $\mathrm{MS} / \mathrm{kg}^{0,75}$.

No presente experimento, não se verificou ocorrência do efeito substitutivo da suplementação, uma vez que não houve redução do consumo de MS do pasto, o que vai de encontro ao princípio de suplementação a pasto (NOLLER et al., 1996; PATERSON et al., 1994; e LUSBY e GILL, 1996), em que o suplemento protéico estimulou o consumo, sem promover efeito substitutivo.

Os resultados obtidos para as características biométricas e produtivas são mostrados na Tabela 2 .

A suplementação com $2 \mathrm{~kg}$ de concentrado (T2) induziu aumento no escore corporal das vacas, sendo maior que nos animais dos demais tratamentos $(\mathrm{P}<0,05)$, demonstrando que o nível de suplementação foi capaz de alterar a condição corporal no período pós-parto.

O peso inicial das vacas não apresentou diferenças entre os diversos tratamentos $(\mathrm{P}>0,05)$. Entretanto, ao final do experimento, o peso das vacas do tratamento sem suplementação foi inferior ao daquelas do tratamento suplementado com $2 \mathrm{~kg}$ de ração por dia $(\mathrm{P}<0,05)$. As pastagens com alta disponibilidade e boa qualidade (Tabela 3), associadas à suplementação, foram suficientes para promover ganho de peso nas vacas após o parto. Este ganho foi 0,$353 ; 0,532$; e $0618 \mathrm{~kg}$ para os animais dos tratamentos T0, T1 e T2, respectivamente, sendo o ganho das vacas do T0 inferior $(\mathrm{P}<0,05)$ ao das vacas do $\mathrm{T} 1 \mathrm{e}$ $\mathrm{T} 2$, que não diferiram entre si $(\mathrm{P}>0,05)$. A variação no ganho, em função da suplementação protéica, também foi observada em vacas Brahman adultas por TRIPLETT et al. (1995).

Os pesos dos bezerros foram avaliados ao final do 
período experimental, não sendo diferentes entre os tratamentos $(\mathrm{P}>0,05)$, sugerindo que a suplementação não influenciou a produção de leite, o que também foi observado por TRIPLETT et al. (1995).

Avaliações do escore da condição corporal dos animais foram realizadas de 14 em 14 dias, com intuito de verificar possíveis modificações dentro de cada tratamento, no período pós-parto. No tratamento 0 (sem suplementação), não se observou alteração do escore da condição corporal das vacas ao longo do período avaliado, mostrando que as pastagens foram suficientes para manutenção da condição inicial. Nos tratamentos em que os animais receberam suplementação ( 1 ou $2 \mathrm{~kg}$ de concentrado por vaca por dia), houve aumento de forma linear do escore da condição corporal (Figura 1).

O ganho no escore da condição corporal também foi encontrado por RUTTER e RANDEL (1984), mas esses autores sugerem que vacas parindo em bom escore da condição corporal mantêm suas funções reprodutivas, se este permanecer sem alteração. Entretanto, na necessidade de promover ganho no pósparto, para restabelecer a atividade ovariana, devemse considerar uso de pastagens de boa qualidade e custo da suplementação (KUNKLE et al., 1994).

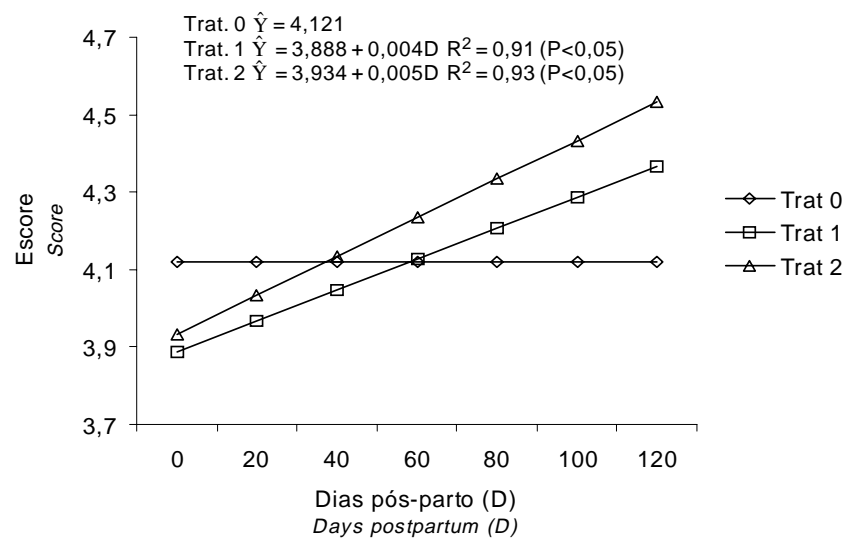

Figura 1 - Escore da condição corporal, em função do número de dias após o parto, em vacas da raça Nelore, submetidas a diferentes níveis de suplementação protéica.

Figure 1 - Score of the body condition on the number of postpartum days, in Nellore cows allotted to different levels of protein supplementation.

\section{Conclusões}

A suplementação protéica não influenciou o consumo de matéria seca do pasto.

A média de ganho de peso diário nos animais recebendo suplementação foi maior que nos nãosuplementados.

A suplementação modificou o escore da condição corporal, em função da quantidade de concentrado.

\section{Referências Bibliográficas}

COCHRAN, R.C., ADAMS, D.C., WALlACE, J.D. et al. 1986. Predicting digestibility of different diets with internal markers: evaluation of four potential markers. J. Anim. Sci., 63(5):1476-1483.

DIAS, F.M.G.N., Efeito da condição corporal, razão peso/ altura e peso vivo sobre o desempenho reprodutivo pósparto de vacas de cortes zebuínas. Belo Horizonte, MG. Escola de Veterinária, 1991. 100p. Dissertação (Mestrado em Zootecnia) - Universidade Federal de Minas Gerais, 1991.

KUNKLE, W.E., SAND, R.S., ERA, D.O. 1994. Effect of body condition on productivity in beef cattle. In: FIELDS, M.J., SAND, R.S. (Eds.) Factors affecting calf crop. Boca Raton: CRC Press. p.167-178.

LUSBY, K., GILL, D. 1996. Suplementação de proteínas: a chave para obter ganhos de peso no gado ao final do verão. Comp. Educ. Cont., 1(1):59-69.

NOLLER, C.H., NASCIMENTO JR., D., QUEIROZ, D.S. Exigências nutricionais de animais em pastejo. In. SIMPÓSIO SOBRE MANEJO DE PASTAGENS, Piracicaba, 1996 Anais...Piracicaba, 1996, p.319-352.

PATERSON, J.A., BELYEA, R.L., BOWMAN, J.P. et al. 1994. The impact of forage quality and supplementation regimen on ruminant animal intake and perfomance. In: FAHEY JR., G.C. (Ed.) Forage quality, evaluation, and utilization. Madison, Wisconsin: American Society of Agronomy. p.59-114.

RANDEL, R.D. 1990. Nutrition and postpartum rebreeding in cattle. J. Anim. Sci., 68(3):853-862.

ROSADO, M.L. Características reprodutiva e biométricas de fêmeas Nelore e F1 Europeu-Nelore. Viçosa, MG:UFV, 1991, 108p. Dissertação (Mestrado em Zootecnia) - Universidade Federal de Viçosa, 1991.

RUTTER, L.M., RANDEL, R.D. 1984. Pospartum nutrient intake and body condition; effect on pituitary function and onset of estrus in beef cattle. J. Anim. Sci., 58(2):265-274.

SHORT, R.E., BELLOWS, R.A., STAIGMILLER, R.B. et al. 1990. Physiologycal mechanisms controlling anestrus and infertility in postpartum beef cattle. J. Anim. Sci., 68(3):799-816.

SILVA, D.J. 1990. Análises de alimentos (Metódos químicos e biológicos). Viçosa, MG: UFV. 156p.

TRIPLETT, B.L., NEUENDORFF, D.A., RANDEL, R.D. 1995. Influence of undegraded intake protein supplementation on milk production, weight gain, and reproductive performance in postpartum Brahman cows. J. Anim. Sci., 73(11):3223-3229.

WETTEMANN, R.P. 1994. Management of nutritional factors affecting the prepartum and postpartum cow. In.: FIELDS, M.J., SAND, R.S. (Eds.) Factors affecting calf crop. Boca Raton: CRC Press. p.155-165.

Recebido em: $12 / 05 / 99$

Aceito em: 08/02/00 